\title{
Polyelectrolyte nanocontainers: controlled binding and release of indomethacin
}

Article

Accepted Version

Mirgorodskaya, A. B., Kushnazarova, R. A., Nikitina, A. V., Semina, I. I., Nizameev, I. R., Kadirov, M. K., Khutoryanskiy, V. V., Zakharova, L. Y. and Sinyashin, O. G. (2018)

Polyelectrolyte nanocontainers: controlled binding and release of indomethacin. Journal of Molecular Liquids, 272. pp. 982989. ISSN 0167-7322 doi:

https://doi.org/10.1016/j.molliq.2018.10.115 Available at https://centaur.reading.ac.uk/80120/

It is advisable to refer to the publisher's version if you intend to cite from the work. See Guidance on citing.

To link to this article DOI: http://dx.doi.org/10.1016/j.molliq.2018.10.115

Publisher: Elsevier

All outputs in CentAUR are protected by Intellectual Property Rights law, including copyright law. Copyright and IPR is retained by the creators or other copyright holders. Terms and conditions for use of this material are defined in the End User Agreement. 


\section{CentAUR}

Central Archive at the University of Reading

Reading's research outputs online 


\title{
Polyelectrolyte nanocontainers: controlled binding and release of indomethacin
}

\author{
Alla B. Mirgorodskaya ${ }^{\mathrm{a}, \mathrm{b}}$, Rushana A. Kushnazarova ${ }^{\mathrm{a}}$, Anastasiya V. Nikitina ${ }^{\mathrm{c}}$, Irina I. Semina ${ }^{\mathrm{c}}$, \\ Irek R. Nizameeva , Marsil K. Kadirova, Vitaliy V. Khutoryanskiyd, Lucia Ya. Zakharova a,b, \\ Oleg G. Sinyashin ${ }^{\mathrm{a}, \mathrm{b}}$
}

${ }^{a}$ Arbuzov Institute of Organic and Physical Chemistry of FRC Kazan Scientific Center of RAS, 8 Arbuzov street, Kazan, 420088, Russian Federation

${ }^{\mathrm{b}}$ Kazan National Research Technological University, 68 K. Marx street, Kazan, 420015, Russian Federation

${ }^{c}$ Kazan State Medical University, 49, Butlerov street Kazan, 420012, Russian Federation

${ }^{\mathrm{d}}$ School of Pharmacy, University of Reading, Whiteknights, PO Box 224, Reading, RG6 6AD, United Kingdom

Corresponding author: Alla Mirgorodskaya; Telephone: +7(843) 27322 93; Fax: +7(843) 27322 53; 8, ul.Akad. Arbuzov, Kazan, 420088, Russia; e-mail:mirgoralla@mail.ru,mirgorod@iopc.ru

\begin{abstract}
Herein, polyelectrolyte capsules containing anti-inflammatory drug indomethacin were formed using layer-by-layer strategy, which involves alternative deposition of oppositely charged polyelectrolytes, such as poly(acrylic acid) and poly(ethyleneimine) (or chitosan) onto the drug substrate. Two variants of encapsulation have been implemented: direct deposition of polyelectrolytes onto indomethacin dispersed in water at $\mathrm{pH} 6$, and preliminary formation of soft matrix by solubilization of indomethacin in micellar solutions of cationic surfactants. The inclusion of indomethacin into nanosized polyelectrolyte capsules (hydrodynamic diameter of three- and five-layer capsules is $90-180 \mathrm{~nm}$ ) has given a new form of indomethacin with the drug content of $0.20-0.25 \%$, which exceeds its limiting solubility in water nearly by the factor of 40 . The choice of materials and procedures used for preparation of capsules, as well as the number of polyelectrolyte layers that form shell has provided the control of the drug release from capsule and resulted in the design of pharmaceutical dosage forms with long-lasting effect.
\end{abstract}

Keywords: polyelectrolyte capsules; indomethacin; layer-by-layer technique 


\section{Introduction}

The development of medicine, pharmacology, and biotechnologies resulted in the growing interest in the design of new systems for encapsulation and delivery of drugs. Recent investigations showed that the objects of supramolecular chemistry represented by amphiphilic compounds and biocompatible polymers can provide background for the design of various types of nanocontainers (micelles, nano- and microemulsions, liposomes, polyelectrolyte capsules, and others), which can retain drugs and preserve them from adverse environmental factors along with their target delivery and long-standing effect [1-9]. These nanocontainers possess several advantages, among which following can be highlighted: (1) simplicity and high processability; (2) nanoscale range, which provides long-lasting circulation in organism; (3) high affinity to cell membranes, (4) microheterogeneous nature of nanosystems, which provides the delivery of both hydrophobic and polar molecules; (5) low concentration range of the compounds, which determines low toxicity of the systems; and (6) sensitivity to external stimuli, which controls drug release. By varying the conditions of synthesis and the structure of building blocks for the preparation of nanocontainers, one can optimize their properties assuming the features of a particular drug and aims of its further application.

In this work, we focused on indomethacin, a non-steroidal anti-inflammatory drug, possessing analgesic, anti-febrile, and antiaggregatory activity [10,11]. However, its wide application is limited because of side effects and poor solubility in water, which decreases its bioavailability [12-16]. Considerable attention is devoted to the solution of this problem. For this purpose, micellar systems, microemulsions, solid lipid and polymeric particles have been explored [17-21]. However, there are still no optimal nanocontainers for indomethacin, which completely meet the requirements for drug delivery systems in living organisms, such as high loading degree, size of less than $200 \mathrm{~nm}$, controlled release of drug, and low toxicity.

In our previous studies, in order to increase the solubility of indomethacin, we used micellar solutions of non-ionic surfactants approved for medicinal and pharmacological applications, as well as solutions of dicationic surfactants [22,23]. On the one hand, the choice of dicationic surfactants was due to the fact that there are data on successful use of indomethacincationic surfactant compositions in ophthalmology and dermatology [24-27]. On the other hand, low critical micelle concentration $(\mathrm{cmc})$ values and a significant solubilization capacity of dicationic surfactants provide their use as cationic agents with a reliable safety, which combine high effectiveness and minimum toxic effects. Using surfactant solutions, we increased the solubility of indomethacin by more than two orders of magnitude [22,23]; however, this was still insufficient to achieve a therapeutically relevant concentration. In addition, micellar systems are dynamic and, therefore, they do not have constant composition. 
Analysis of recent publications in addition to our experience [28-33] allowed us to conclude that polyelectrolyte micro- and nanocapsules are promising for the design of containers for drug delivery. An important advantage of these capsules is the ability to control their protective properties and the drug release by the directional screening of the materials for the formation of shell, as well as the conditions of their formation and operation.

To prepare nanocontainers, we chose the layer-by-layer (LbL) technique, involving adsorption of oppositely charged polyelectrolytes onto the surface of colloidal particles [34-36]. This method is characterized by simplicity, high reproducibility, cost effectiveness, quick nature of the process, and the preparation of homogeneous nanosized particles. To design these capsules, a broad range of natural (polysaccharides and polypeptides) and synthetic (poly(acrylic acid), sodium polystyrene sulfonate, and poly(allylamine hydrochloride)) polyelectrolytes is available [37-42]. These features justify the marked advantages of layer-by-layer deposition over alternative techniques, e.g. polymerization, coacervation, and so on. There are different modifications of the protocols of encapsulation of organic compounds using layer-by-layer method. Two of them are the most popular, namely, direct deposition of polyelectrolytes onto substrate, which is successfully used only in the case of charged compounds; and the preliminary inclusion of the substrate into the sacrificial matrix, which assumes the destruction and removal of excipient materials after the formation of polyelectrolyte shell [43-48]. Recently, reports appeared on the procedures, which consider the preliminary solubilization of uncharged compounds using the micelles of ionic surfactant. The charged surfactant-substrate complex acts as a "soft" template, which could be used for layer-by-layer deposition of polyelectrolytes [31$33,49]$.

In this work, we aimed at the preparation of nanosized polyelectrolyte capsules loaded with indomethacin, which provides prolonged release and protects against adverse environmental effects. For shell formation, poly(acrylic acid) (PAA) was used as a polyanion, while poly(ethylene imine) (PEI) or low-molecular weight chitosan acted as polycations. In this study, two variants of the capsules preparation were used: (1) direct deposition of polyelectrolytes onto indomethacin dispersed in aqueous solution or (2) the protocol, involving preliminary solubilization of indomethacin in micellar solutions of cationic surfactants with the formation of a charged indomethacin-surfactant complex. In order to solubilize indomethacin, the following cationic surfactants were used: cetyltrimethylammonium bromide (CTAB) and hexamethylene1,6-bis(dimethylhexadecylammonium dibromide (16-6-16). Structural formulas of the compounds are given below. 


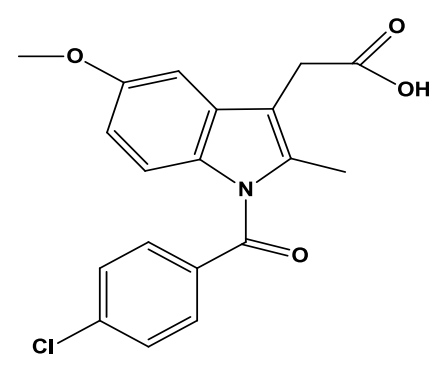

Indomethacin

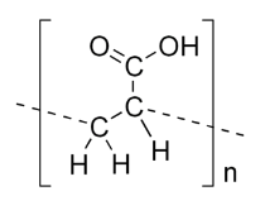

PAA

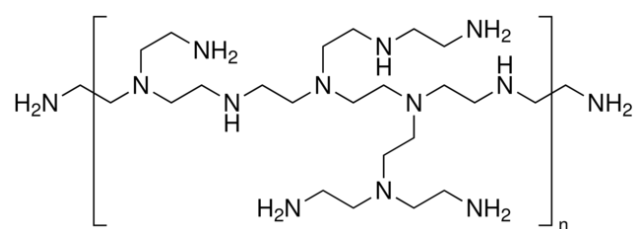

PEI

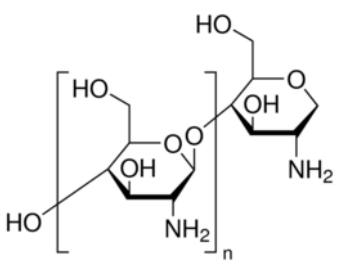

Chitosan<smiles>C[N+](C)(C)c1ccccc1</smiles>

CTAB<smiles>CN(C)CC[N+](C)(C)C</smiles>

$16-6-16$

This work involved the following stages: (1) formation of three-, five-, and seven-layered capsules using various modifications of LbL method; (2) evaluation of losses of indomethacin during encapsulation; (3) determination of size and surface charge of capsules; (4) evaluation of their penetration ability; and (5) determination of the toxicity of drug loaded capsules.

\section{Materials}

Indomethacin with $99 \%$ of purity was purchased from Sigma-Aldrich and used as received. To form polyelectrolyte capsules, PAA (MW 1800 Da), branched PEI (MW 25000 Da), and lowmolecular weight chitosan (MW 50,000-190,000 Da) (Sigma-Aldrich) were used. To prepare micellar solutions, CTAB (Sigma-Aldrich) or dicationic surfactant 16-6-16 were used. 16-6-16 was synthesized by the reaction of $\mathrm{N}, \mathrm{N}, \mathrm{N}^{\prime}, \mathrm{N}^{\prime}$-tetramethyl-1,6-hexamethylenediamine with excess $n$-hexadecyl bromide in acetone followed by double recrystallization from ethyl alcohol according to the procedure from [50]. Some synthetic details are given in Supporting information.

\subsection{Preparation of polyelectrolyte capsules}

Polyelectrolyte capsules were formed using layer-by-layer technique using a template composed of micellar solutions of cationic surfactants with solubilized indomethacin forming a positively charged surfactant/drug complex. In this procedure, $0.0075 \mathrm{~g}$ of indomethacin was added into 6 $\mathrm{mL}$ of $1.2 \cdot 10^{-4} \mathrm{~mol} / \mathrm{L}$ aqueous solution of dicationic surfactant 16-6-16 (when CTAB was used its concentration was $3 \cdot 10^{-3} \mathrm{~mol} / \mathrm{L}$ ) and stirred for $30 \mathrm{~min}$ at $1000 \mathrm{rpm}$. Then this mixture was 
centrifuged at $13000 \mathrm{rpm}$ for $13 \mathrm{~min}$ and the precipitate was isolated. After that, $8 \mathrm{~mL}$ of 1 $\mathrm{mg} / \mathrm{mL}$ PAA was added to this precipitate and vigorously stirred for $5 \mathrm{~min}$. The centrifugation was repeated and the precipitate was isolated. Similar procedure was used with PEI (or chitosan): $8 \mathrm{~mL}$ of $1 \mathrm{mg} / \mathrm{mL}$ polyamine solution was added to the precipitate followed by stirring and centrifugation. $\mathrm{pH}$ 6-7 was maintained in all solutions during this procedure. The $\mathrm{pH}$ of solutions was adjusted using $\mathrm{HCl}$ or $\mathrm{NaOH}$ and it was controlled using a Hanna 213 pH-meter equipped with a HI 1330 electrode. Depending on the task, the procedure for deposition of polyelectrolytes was repeated and capsules with the specified number of layers were prepared. After deposition of the last layer of polyanion, the precipitate was separated and $4 \mathrm{~mL}$ of bidistilled water was added for further storage and testing of the capsules.

An alternative procedure for encapsulation of indomethacin was used for direct deposition of polyelectrolyte shell onto the dispersed drug. The method for encapsulation is analogous to that described above; however, in this case, the polycation layer was deposited first. In this procedure, $0.0075 \mathrm{~g}$ of indomethacin was added into $6 \mathrm{~mL}$ of water $(\mathrm{pH}$ 7) and stirred for $15 \mathrm{~min}$ at $1000 \mathrm{rpm}$. After that, $8 \mathrm{~mL}$ of $1 \mathrm{mg} / \mathrm{mL}$ PEI (or chitosan) was added and vigorously stirred for $5 \mathrm{~min}$. Then this mixture was centrifuged at $13000 \mathrm{rpm}$ for $15 \mathrm{~min}$ and the precipitate was isolated. After that, $8 \mathrm{~mL}$ of $1 \mathrm{mg} / \mathrm{mL}$ PAA was added to this precipitate and vigorously stirred for $5 \mathrm{~min}$ and precipitate was isolated by centrifugation. The procedure for deposition of polyelectrolytes can be repeated and capsules with the specified number of layers were prepared. The capsules prepared using this method were positively charged.

\subsection{Control of losses of indomethacin during encapsulation}

Losses of indomethacin at each stage of capsule formation were controlled by spectrophotometry using Specord 250 Plus spectrophotometer (Germany). For this purpose, solutions remaining after the deposition of each polyelectrolyte layer were collected and their absorbance (D) at 327 $\mathrm{nm}$ was determined. The concentration of indomethacin $(\mathrm{C})$ in the supernatant was evaluated using Lambert-Beer equation $\mathrm{C}=\mathrm{D} /(\varepsilon \times \mathrm{L})$, where $\varepsilon$ is the molecular absorption coefficient corresponding to $5800 \mathrm{~mol} /(\mathrm{L} \mathrm{cm})[22,23]$, in the case of indomethacin in neutral media and $\mathrm{L}$ is the optical path length. Then, assuming the volume of filtered solutions, the total content of indomethacin was determined and the losses at each stage of capsule formation were evaluated. The encapsulation efficiency (EE,\%) and loading capacity (LC) were evaluated from equations:

$$
\begin{aligned}
& E E(\%)=\frac{\text { Total amount }_{\text {ind }}-\text { Free }_{\text {ind }}}{\text { Total amount }_{\text {ind }}} \times 100 \%, \\
& L C(\%)=\frac{\text { Total amount }_{\text {ind }}-\text { Free }_{\text {ind }}}{\text { Total amount of polyelectr olyte }} \times 100 \% .
\end{aligned}
$$




\subsection{Determination of size and charge of capsules}

Sizes and zeta potential of polyelectrolyte capsules were determined using Malvern ZetaSizer Nano (Malvern Instruments, UK). The source of laser radiation was a He-Ne gas laser with the power of $10 \mathrm{~mW}$ and the wavelength of $633 \mathrm{~nm}$. The light scattering angle is $173^{\circ}$. The pulse accumulation time is 5-8 min. The signals were analyzed using a single-plate multichannel correlator coupled with IBM PC compatible computer equipped with the software package for the evaluation of effective hydrodynamic radius of dispersed particles.

Transmission electron microscopy (TEM) images were obtained on a Hitachi HT7700 TEM instrument (Japan) operated at $110 \mathrm{kV}$ accelerating voltage. The samples were dispersed on 300 mesh copper grids with continuous carbon-formvar support films.

\subsection{Drug release studies}

The release of indomethacin from capsules was studied using dialysis method. To carry out these studies, aqueous solution containing capsules with imdomethacin was transferred into the dialysis bag with the molecular weight cut-off $40 \mathrm{kDa}$, which was then immersed into the beaker containing a total of $100 \mathrm{~mL}$ of phosphate buffer solution $(\mathrm{pH} \mathrm{6.86})$. The process was conducted at constant stirring maintaining the temperature of the medium at $37^{\circ} \mathrm{C}$. After particular time intervals, aliquots were taken from the solution and their absorbance at $327 \mathrm{~nm}$ was measured using spectrophotometer, and the concentration of indomethacin (C) was evaluated using Lambert-Beer equation. Using these data, the dependence was plotted, which reflects the change in the drug concentration with time. This dependence reached a plateau in the end of the drug release from capsules. Each experiment was repeated at least 3 times. Experimental data were analized by nonlinear least squares regression, using Origin Pro 8.5 software.

\subsection{Determination of toxicity of indomethacin loaded into polyelectrolyte capsules}

Investigation of acute toxicity was carried out according to ref [51,52]. In brief, 96 outbred male mice weighing 22-24 g and 84 male rats weighing 180 - $220 \mathrm{~g}$ were used in these experiments. Each dose was administered intraperitoneally and intragastrically to six mice and six rats. The mortality rate was observed in all the doses after 24 and $48 \mathrm{hrs}$. The experiment was repeated in triplicates with each concentration. $\mathrm{LD}_{50}$ was calculated by graphical method from dependence of percent mortality versus indomethacin concentration. For subsequent verification, $\mathrm{LD}_{50}$ values were obtained by graphical methods of Dragstedt-Behrens as given by Carpenter [53]. 
All experiments involving animals were performed in accordance with the guidelines set by the European Communities Council Directive (1997). All in vivo experiments reported in this work were approved by the Ethical Committee of Kazan State Medical University (approval number 5 from 28th May 2012). Animals were housed in stainless steel cages, were fed with standard multiration pellets for rodents (Effect Ltd., Chapaevsk, Russian Federation), and had unlimited access to water.

\section{Results and discussion}

\subsection{Size and charge of polyelectrolyte capsules loaded with indomethacin}

Among various LbL methods, we selected two alternative protocols of shell formation for the preparation of polyelectrolyte capsules with encapsulated indomethacin. The first protocol involved solubilized form of the drug using micelles of cationic surfactants and the second protocol utilized a direct deposition of polyelectrolytes onto the dispersed drug. In the former case, the drug/surfactant complex is formed, which has a positive surface charge before deposition of the first layer of a polyanion. This enhances electrostatic interactions in the system and affects capsule size. As a surfactant, we employed conventional CTAB and its dicationic counterpart 16-6-16 characterized by a significantly lower threshold of micelle formation and high solubilization capacity [8]. The direct deposition of polyelectrolyte shell onto indomethacin was carried out at pH 6-7. Since indomethacin has a $\mathrm{pK}$ of 4.5 [54], it is almost completely ionised under $\mathrm{pH}$ conditions used. In this case, the polycation layer is deposited first and the surface of the capsule bears positive charge.

The number of polyelectrolyte layers was varied from 3 to 7 . The scheme of the encapsulation of indomethacin involving its prior solubilization in micelles is shown in Fig.1.

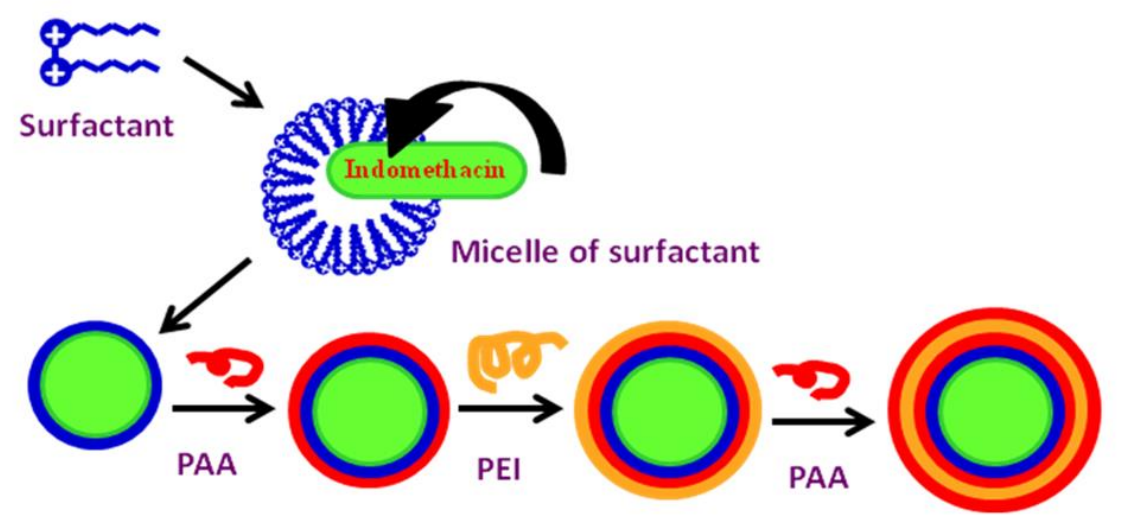

Fig.1. Scheme of formation of polyelectrolyte capsules. 
Investigation of the properties of capsules involved the determination of their size and charge, evaluation of the encapsulation efficiency, and studies of drug release.

Using electrophoretic light scattering, electrokinetic potential ( $\zeta$-potential) of particles was monitored during the encapsulation (Fig.2). These data show the recharging of the system in the process of shell formation. The final potential of the particles is shown to be determined by the charge of polyelectrolytes and the order of deposition of layers; e.g. in the case of three-layer capsules CTAB/PAA/PEI/PAA loaded with indomethacin, $\zeta$-potential is $-50--55 \mathrm{mV}$. Sizes of the capsules were determined using dynamic light scattering. It was shown that the size distribution of capsules is unimodal and is characterized by a polydispersity index of $0.1-0.3$. In the case of three-layered capsules when using micellar solution of CTAB as a template, their hydrodynamic diameter is $190 \pm 11 \mathrm{~nm}$, while in the case of dicationic surfactant 16-6-16 the particle size was smaller $(90-110 \mathrm{~nm})$. The particle size increased slightly with an increase in the number of layers (Fig. 3); e.g. 5- and 7-layered capsules had their diameter around $120 \pm 9 \mathrm{~nm}$ and $140 \pm 10 \mathrm{~nm}$, respectively.

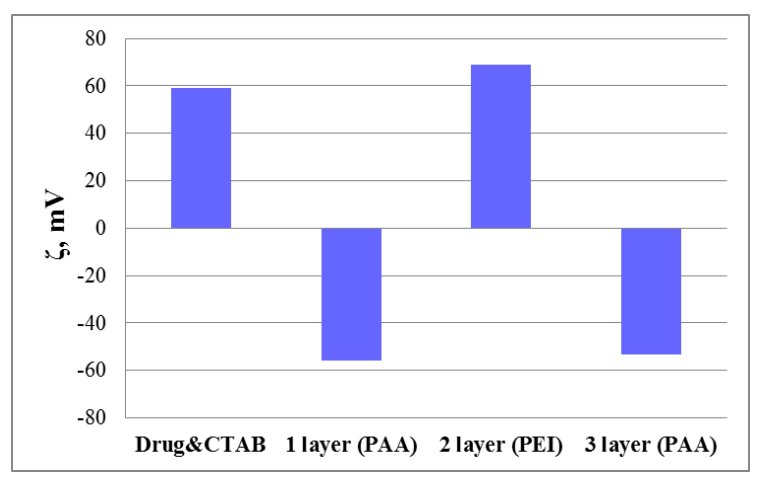

Fig.2. Change of zeta-potential of particles during capsule formation.

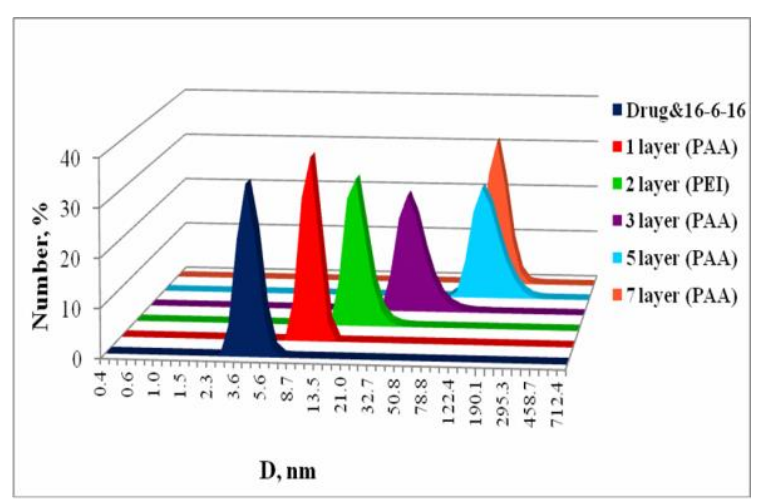

Fig.3. Change of hydrodynamic diameter of 16-6-16/PAA/PEI capsules loaded with indomethacin after each deposited layer of polyelectrolytes. 


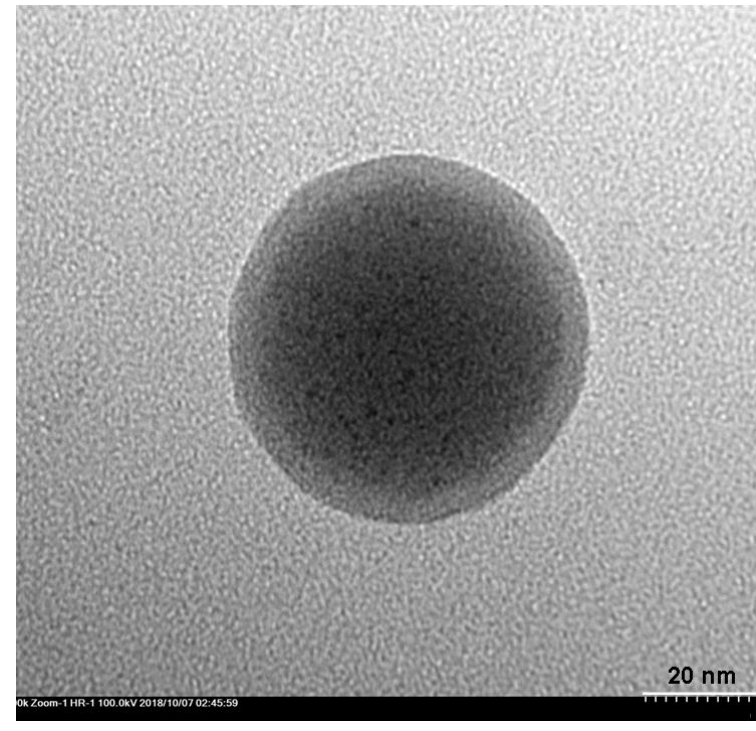

Fig.4. TEM images of 3-layered capsules 16-6-16/PAA/PEI loaded with indomethacin.

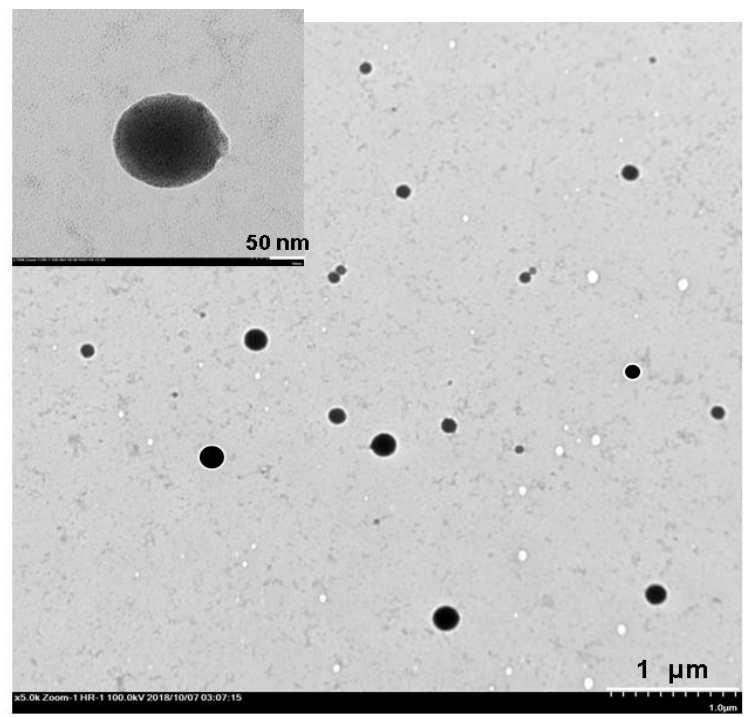

Fig.5. TEM images of 5-layered capsules 16-6-16/PAA/PEI loaded with indomethacin.

Images obtained by transmission electron microscopy (Figs. 4,5) demonstrate that capsules are spherical. The diameter of particles is $60-100 \mathrm{~nm}$ for 3-layered capsules and 120-150 nm for 5-layered capsules. These results are in good agreement with the DLS data.

Using spectrophotometry, the losses of indomethacin during synthesis were evaluated. It was determined that losses were $40 \%$ when using dicationic surfactant 16-6-16, while in the case of CTAB they were greater than $50 \%$. Thus, dicationic surfactant possessing better solubilization capacity than its monocationic counterpart provides an increase in the encapsulation efficiency and the formation of the particles with a smaller size than in the case of CTAB. The substitution of PEI by natural polycation chitosan gave three-layered capsules with the hydrodynamic diameter of $105 \pm 12 \mathrm{~nm}$; in this case, losses of indomethacin during synthesis were around $50 \%$. 
Through the alternating PEI/PAA (or chitosan/PAA) deposition directly onto dispersed indomethacin, three-layered positively charged capsules are formed, with a zeta potential of 65$70 \mathrm{mV}$ and hydrodynamic diameter of 170-180 nm and losses of preparation upon the LbL process of ca. $50-60 \%$. Thus, by varying the conditions of capsule preparation, one can prepare nanosized polyelectrolyte capsules loaded with indomethacin with various surface charges. This can be an essential factor determining mucoadhesive properties of the pharmaceutical form of indomethacin [55].

An important aspect of the preparation of capsules is their loading capacity. For this reason, a series of experiments were carried out, where the ratio and concentration of surfactant and indomethacin were varied upon the formation of micellar template. The main problem was the precipitation of free indomethacin during this procedure. Maximum loading was obtained under the conditions described in Experimental section when using dicationic surfactant 16-6-16; in this case, nanosized polyelectrolyte capsules with $0.20-0.25 \%$ of loaded indomethacin were prepared, which is nearly 40 times as high as its maximum solubility in water.

\subsection{Release of indomethacin from polyelectrolyte capsules}

An important feature of polyelectrolyte capsules is their ability for a gradual drug release. This process was controlled by dialysis followed by spectrophotometric determination of the concentration of drug released. We adopted the procedure, which was suggested for determination of the release of indomethacin from polyelectrolyte films [17] using a phosphate buffer ( $\mathrm{pH}$ 6.86) as a receiving medium atat $37^{\circ} \mathrm{C}$. In addition, we varied $\mathrm{pH}$ of medium in some experiments in order to evaluate the impact of this factor on the penetration ability of the capsule shell. In addition, we varied $\mathrm{pH}$ of medium in some experiments in order to evaluate the impact of this factor on the penetration ability of the capsule shell in vitro.

Fig.6 illustrates the changes in the absorption spectra of the dialysate solutions with time resulting from the release of indomethacin from capsules into the bulk medium. An increase in the absorbance of the solution at maximum (Figs.7 and 8) reflects the release of indomethacin, which depends on the nature of polyelectrolytes, the order and the number of deposited layers, as well as the contribution of electrostatic interactions between layers controlled by the change of $\mathrm{pH}$. Some average characteristics of the capsules obtained from several independent experiments, are given in Table 1. 


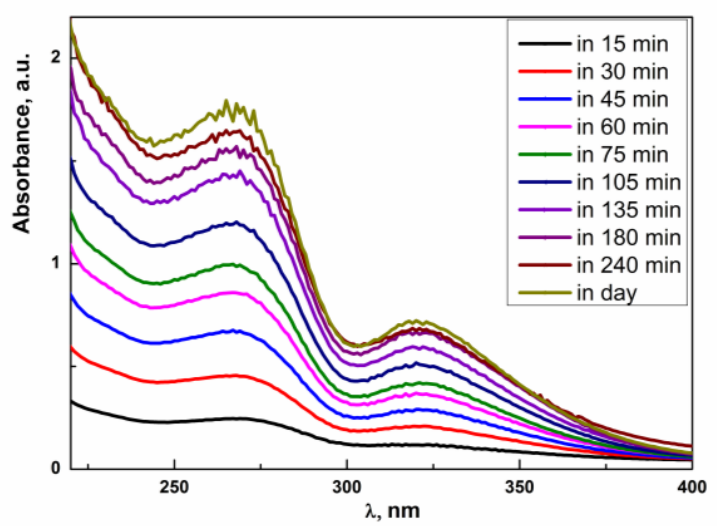

Fig.6. Change in the absorbance of dialysate solutions (indomethacin) with time (three-layered capsules based on $\mathrm{CTAB} / \mathrm{PAA} / \mathrm{PEI}, 37^{\circ} \mathrm{C}, \mathrm{pH}$ 7).

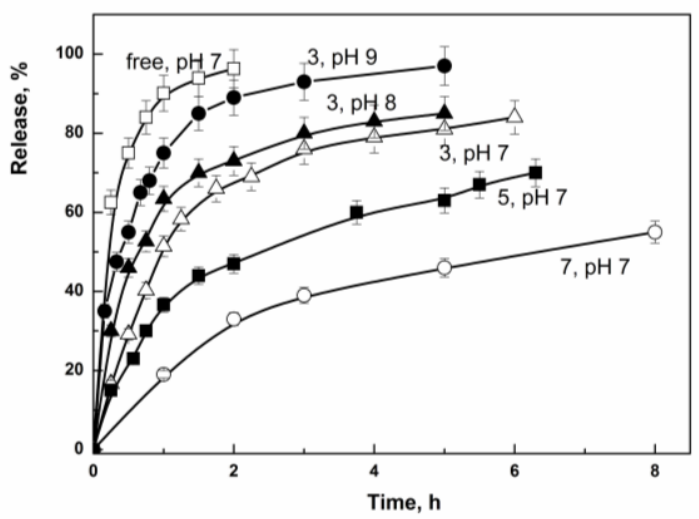

Fig.7. Release of free and encapsulated indomethacin from dialysis bag (three-, five-, and sevenlayered capsules 16-6-16/PAA/PEI, $37^{\circ} \mathrm{C}$, pH 7-9).

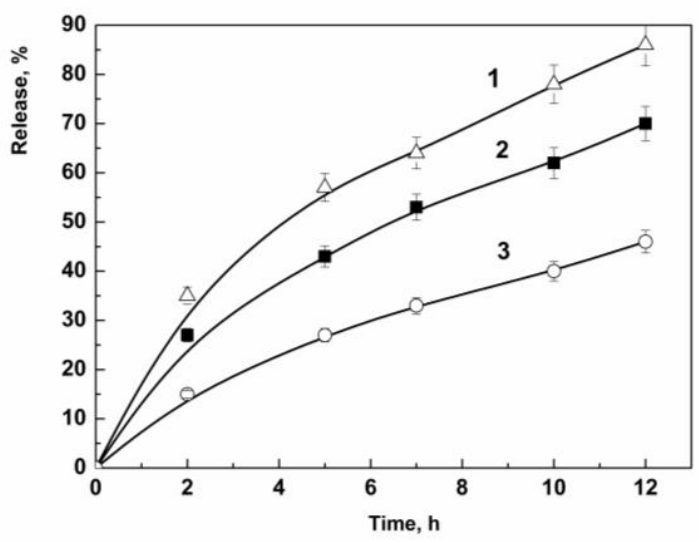

Fig.8. Release of indomethacin from three-layered capsules 16-6-16/PAA/chitosan at pH 8 (1), $\mathrm{pH} 7$ (2), as well as from the five-layered capsules at $\mathrm{pH} 7(3)\left(37^{\circ} \mathrm{C}\right)$. 
Table 1. Size of the polyelectrolyte capsules loaded with indomethacin and drug release characteristics.

\begin{tabular}{|c|c|c|c|c|c|c|c|c|}
\hline \multirow[t]{2}{*}{ Shell } & \multirow[t]{2}{*}{ Template } & \multirow{2}{*}{$\begin{array}{l}\text { Number } \\
\text { of layers }\end{array}$} & \multirow[t]{2}{*}{$\mathrm{EE}, \%$} & \multirow[t]{2}{*}{$\mathrm{LC}, \%$} & \multirow[t]{2}{*}{$\mathrm{D}_{\mathrm{h}}, \mathrm{nm}$} & \multirow[t]{2}{*}{$\mathrm{pH}$} & \multicolumn{2}{|c|}{$\begin{array}{c}\text { Released } \\
\text { indomethacin, \% }\end{array}$} \\
\hline & & & & & & & $2 \mathrm{~h}$ & $5 \mathrm{~h}$ \\
\hline \multirow[t]{2}{*}{ PAA/PEI } & \multirow[t]{2}{*}{ CTAB } & \multirow[t]{2}{*}{3} & \multirow[t]{2}{*}{$46 \pm 5$} & \multirow[t]{2}{*}{$14 \pm 1.5$} & \multirow[t]{2}{*}{$190 \pm 20$} & 7 & $72 \pm 3$ & $89 \pm 4$ \\
\hline & & & & & & 7 & $66 \pm 2$ & $80 \pm 3$ \\
\hline \multirow{2}{*}{ PAA/PEI } & \multirow{2}{*}{$16-6-16$} & \multirow{2}{*}{3} & \multirow{2}{*}{$60 \pm 3$} & \multirow{2}{*}{$17 \pm 1$} & \multirow{2}{*}{$100 \pm 10$} & 8 & $73 \pm 3$ & $85 \pm 3$ \\
\hline & & & & & & 9 & $87 \pm 4$ & $94 \pm 4$ \\
\hline PAA/PEI & $16-6-16$ & 5 & $60 \pm 3$ & $13 \pm 1$ & $120 \pm 9$ & 7 & $47 \pm 2$ & $63 \pm 3$ \\
\hline PAA/PEI & $16-6-16$ & 7 & $60 \pm 3$ & $9 \pm 0.8$ & $140 \pm 11$ & 7 & $33 \pm 2$ & $46 \pm 2$ \\
\hline PAA/Chitosan & $16-6-16$ & 3 & $50 \pm 4$ & $15 \pm 0.5$ & $105 \pm 12$ & 7 & $24 \pm 2$ & $43 \pm 3$ \\
\hline PEI/PAA & $\begin{array}{l}\text { Without } \\
\text { surfactant }\end{array}$ & 3 & $55 \pm 5$ & $13 \pm 1$ & $110 \pm 15$ & 7 & $45 \pm 2$ & $74 \pm 3$ \\
\hline
\end{tabular}

The analysis of the data reveals that the release of encapsulated indomethacin occurs significantly slower compared to the permeation of free drug through the dialysis membrane; that is, the diffusion of the drug through the shell is a rate-determining step. This observation indicates the possibility of using these polyelectrolyte capsules as pharmaceutical forms for drug delivery with long-lasting effect.

The capsules with CTAB as a micellar template were found to be more permeable for indomethacin than those prepared with 16-6-16 surfactant. With an increase in the number of layers, the permeability of capsules decreases; e.g. the transition from three-layered to sevenlayered capsules slows down this process nearly by two times. The capsules, formed by the direct deposition of polyelectrolytes onto indomethacin are slightly less permeable for the drug than those, prepared with micellar template. Substitution of PEI by natural polyelectrolyte chitosan results in a significant inhibition of the release of indomethacin. For example, $66 \%$ of indomethacin is released within $2 \mathrm{~h}$ in the former case, while in the latter case its release is only $24 \%$ within the same time.

An important factor responsible for the release of encapsulated substrate is the solution $\mathrm{pH}$ : the release of indomethacin is facilitated with the growth in $\mathrm{pH}$ (Fig.7). This can be rationalized by the change in the charge of polyelectrolytes, weakening of binding of macromolecules, and softening of shell. It can be suggested that the destruction of capsules would occur at a critical $\mathrm{pH}$ value and the release of indomethacin would be related to this process. 
In order to evaluate the stability of the capsules loaded with indomethacin, monitoring of release processes was accompanied by the determination of particle size. The results obtained by dynamic light scattering are given in Fig.9 (a,b), which show that the particle size distribution remains unchanged for a long time in the range of pH 5-7 (Fig.9 a). The data obtained at pHs > 7.5 indicate instability of the system, which increases as the $\mathrm{pH}$ rise. To illustrate this, we placed the capsules in a solution at $\mathrm{pH}$ 9.2. Both larger and smaller aggregates appear with time on the diagram of particle distribution at $\mathrm{pH}$ 9.2, with polydispersity index increasing and unimodal distribution distorted in some cases (Fig.9 b). All this suggests that capsules are partially broken and the release of indomethacin is primarily related to this process.
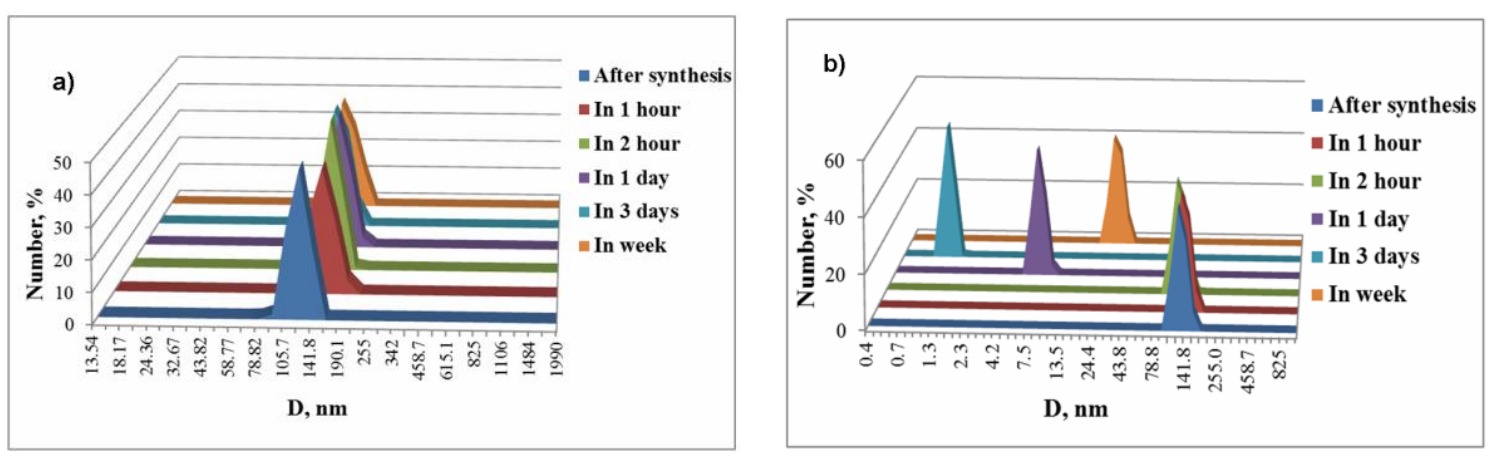

Fig.9. Changes in particle size distributions of three-layered capsules with time at $\mathrm{pH} 7$ (a), pH $9.2(\mathrm{~b})$.

Similar result was obtained in the case of decrease in solution pH. (Fig.S3). For example, under $\mathrm{pH} 4.5$, the release of indomethacin from a three-layer capsule is approximately one and a half times higher compared to neutral $\mathrm{pH}$ due to decrease of contribution of anionic form of PAA.

To study the indometacin release from capsules the kinetic model of Ritger - Peppas [56] has been used. This simple semi-empirical model is fully sufficient for spherical delivery systems [57-59] and given by equation:

$$
\frac{M_{t}}{M_{\text {inf }}}=k_{l} t^{n},
$$

here $M_{t}$ and $M_{\text {inf }}$ are absolute cumulative amounts of drug released at time $t$ and infinite time; $k$ is a constant incorporating structural and geometric characteristics of the particles, and $n$ is the release exponent, indicative of the mechanism of drug release. In the case of spherical delivery systems when $\mathrm{n}=0.43$ drug release mechanism is Fician diffusion. An $n$ value of 1 corresponds to zero-order release kinetics (case II transport); $0.43<n<1$ means an anomalous (non-Fickian) 
diffusion release model; and $n>1$ indicates a super case II transport relaxational release [56]. The results obtained by fitting the release data in terms of Peppas equation are summarized in Table 2 and Fig. S4. As can be seen $\mathrm{n}$ values obtained at $\mathrm{pH} 7-8$ rang mainly around values of 0.4-0.5, which allows one to assume that the drug release mechanism is Fician diffusion. Values of $n$ slightly increase with an increase in the number of layers deposited; they are somewhat higher for chitosan based capsules. For PAA/PEI capsules a decrease of $n$ values at $\mathrm{pH} \geq 8$ can be due to the fact that diffusion of drug from capsules is additionally contributed by partial desintegration of capsule shells thereby enhancing drug release. In the case of PAA/chitosan capsules $\mathrm{n}$ value of 0.49 at $\mathrm{pH} 8$ probably testifies that the integrity of capsules is preserved. The $\mathrm{k}$ values characterizing the diffusion rate depending on the structure of capsules decrease with an increase of the number of layers; they are somewhat lower for the chitosan based capsules. The latter can be of importance upon the fabrication of drug delivery systems with prolonged released of the drug.

Table 2. Parameters obtained upon fitting experimental data (Figs 7,8) to Ritger-Peppas model.

\begin{tabular}{ccccc}
\hline capsule & $\begin{array}{c}\text { Number of } \\
\text { layers }\end{array}$ & $\mathrm{pH}$ & $\mathrm{k}$ & $\mathrm{n}$ \\
\hline PAA/PEI & 3 & 9 & $0.70 \pm 0.019$ & $0.26 \pm 0.027$ \\
PAA/PEI & 3 & 8 & $0.57 \pm 0.019$ & $0.28 \pm 0.030$ \\
PAA/PEI & 3 & 7 & $0.47 \pm 0.025$ & $0.41 \pm 0.043$ \\
PAA/PEI & 5 & 7 & $0.34 \pm 0.012$ & $0.42 \pm 0.024$ \\
PAA/PEI & 7 & 7 & $0.23 \pm 0.017$ & $0.45 \pm 0.046$ \\
PAA/chitosan & 3 & 8 & $0.25 \pm 0.009$ & $0.49 \pm 0.016$ \\
PAA/chitosan & 3 & 7 & $0.18 \pm 0.006$ & $0.53 \pm 0.015$ \\
PAA/chitosan & 5 & 7 & $0.01 \pm 0.003$ & $0.61 \pm 0.015$ \\
\hline
\end{tabular}

The potential of in vivo application of indomethacin-loaded polyelectrolyte capsules leads to the need to evaluate their safety. For this reason, we investigated acute toxicity of three-layered empty and indomethacin-loaded capsules based on poly(acrylic acid)/chitosan. The experiments were carried out in mice and rats by intraperitoneal injection (i.p.) and direct intragastric administration (Table 3). 
Table 3. Parameters of acute toxicity of free indomethacin and indomethacin-loaded nanocapsules during administration to laboratory animals.

\begin{tabular}{clc}
\hline No. & Substance & LD $_{50}(\mathrm{mg} / \mathrm{kg})$ \\
\hline 1 & Indomethacin i.p. to mouse & $19 \pm 5$ \\
2 & Indomethacin i.p. to rat & $21 \pm 7$ \\
3 & Nanocapsules with indomethacin i.p. to mouse & $42 \pm 7$ \\
4 & Nanocapsules with indomethacin i.p. to rat & $43 \pm 9$ \\
5 & Indomethacin intragastrically to mouse & $36 \pm 6$ \\
6 & Indomethacin intragastrically to rat & $32 \pm 7$ \\
7 & $\begin{array}{l}\text { Nanocapsules with indomethacin intragastrically to } \\
8\end{array}$ & Nanocapsules with indomethacin intragastrically to rat \\
9 & $\begin{array}{l}\text { Nanocapsules without indomethacin intragastrically to } \\
\text { mouse }\end{array}$ & $\begin{array}{c}\text { Not detected up to } \\
2000 \mathrm{mg} / \mathrm{kg}\end{array}$ \\
10 & $\begin{array}{l}\text { Nanocapsules without indomethacin intragastrically to } \\
\text { rat }\end{array}$ & $\begin{array}{c}\text { Not detected up to } \\
3000 \mathrm{mg} / \mathrm{kg}\end{array}$ \\
\hline
\end{tabular}

Our results on intraperitoneal administration of free indomethacin provided $\mathrm{LD}_{50}$ values of $19 \pm 5 \mathrm{mg} / \mathrm{kg}$ (in mice) and $21 \pm 7 \mathrm{mg} / \mathrm{kg}$ (in rats), which broadly agrees with the literature data $(13 \pm 3$ and $15 \pm 3 \mathrm{mg} / \mathrm{kg}$, respectively [60]). The empty capsules were found to be nontoxic, with lethal doses not detected even at the maximum injected concentration of $2000 \mathrm{mg} / \mathrm{kg}$. The value of $\mathrm{LD}_{50}(\mathrm{mg} / \mathrm{kg})$ of the capsules containing indomethacin was greater than that for the free drug introduced into organism as an aqueous suspension. This result is independent of the route of administration, i.e. intraperitoneal injection or intragastric administration, and is reproduced for tests both on mice and rats. Capsules prepared in this study may be considered as drug carriers alternative to other types of nanocontainers, e.g. indomethacin-loaded polymeric nanoparticles prepared from self-assembled amphiphilic N-vinylpyrrolidone, for which $\mathrm{LD}_{50}$ is $50-70 \mathrm{mg} / \mathrm{kg}$ [54]. Meanwhile, the possibility of tuning the capsule properties by the variation of the number and order of layer deposition, including the simple way of the control of drug release provides them potential advantage for practical applications.

\section{Conclusions}

Encapsulation protocol has been developed for a model anti-inflammatory drug indomethacin using layer-by-layer strategy, which involves the alternating deposition of oppositely charged polyelectrolytes, such as poly(acrylic acid) and poly(ethylene imine) (or chitosan) onto the drug substrate. Two variants of encapsulation have been implemented: 1) direct deposition of polyelectrolytes onto indomethacin dispersed in water at $\mathrm{pH} 6$, which 
assumes the deposition of polycation (PEI) as the first layer. In this case, the particles carrying positive charge are obtained (zeta potential is $+65-70 \mathrm{mV}$ ); 2) preliminary formation of soft matrix by solubilization of indomethacin in micellar solutions of cationic surfactants yielding the capsules with negative charge on their surface (zeta potential is -50 to $-55 \mathrm{mV}$ ). The hydrodynamic diameter of three- and five-layered capsules is $90-180 \mathrm{~nm}$ and losses of indomethacin during capsule preparation are $\leq 50 \%$.

The inclusion of indomethacin into nanosized polyelectrolyte capsules has resulted in a new form of indomethacin with the content of the loaded drug of $0.20-0.25 \%$ that exceeds its limiting solubility in water nearly by a factor of 40 . The choice of materials and procedures used for preparation of capsules, as well as the number of polyelectrolyte layers that form capsule shell has provided the possibility to control drug release. These capsules are of potential interest for design of pharmaceutical forms with long-lasting effects.

\section{Acknowledgements}

This work is supported by the Russian Science Foundation (grant № 14-23-00073). 


\section{References}

[1] N. Amirmahani, N.O. Mahmoodi, G.M. Mohammadi, A. Ghavidast, Advances in nanomicelles for sustained drug delivery, J. Ind. Eng. Chem. 55 (2017) 21-34.

[2] A. Larrañaga, M. Lomora, J.R. Sarasua, C.G. Palivan, A. Pandit, Polymer capsules as micro/nanoreactors for therapeutic applications: Current strategies to control membrane permeability, Prog. Mater. Sci. 90 (2017) 325-357.

[3] R.S. Elezaby, H.A. Gad, A.A. Metwally, A.S. Geneidi, G.A. Awad, Self-assembled amphiphilic core-shell nanocarriers in line with the modern strategies for brain delivery, $\mathrm{J}$. Controlled Release 261 (2017) 43-61.

[4] T. Ramasamy, H.B. Ruttala, B. Gupta, B.K. Poudel, H.-G. Choi, C.S. Yong, J.O. Kim, Smart chemistry-based nanosized drug delivery systems for systemic applications: A comprehensive review, J. Controlled Release 258 (2017) 226-253.

[5] T.N. Pashirova, I.V. Zueva, K.A. Petrov, V.M. Babaev, S.S. Lukashenko, I.K. Rizvanov, E.B. Souto, E.E. Nikolsky, L.Ya. Zakharova, P. Masson, O.G. Sinyashin, NanoparticleDelivered 2-PAM for rat brain protection against paraoxon central toxicity, ACS Appl. Mater. Interfaces 9 (20) (2017) 16922-16932.

[6] L. Crawford, J. Rosch, D. Putnam, Concepts, technologies, and practices for drug delivery past the blood-brain barrier to the central nervous system, J. Controlled Release 240 (2016) 251-266.

[7] M.M. Wen, N.S. El-Salamouni, W.M. El-Refaie, H.A Hazzah, M.M. Ali, G. Tosi, R.M. Farid, M.J. Blanco-Prieto, N Billa, A.S. Hanafy, Nanotechnology-based drug delivery systems for Alzheimer's disease management: Technical, industrial, and clinical challenges, J. Controlled Release, 245 (2017) 95-107.

[8] L.Ya. Zakharova, R.R. Kashapov, T.N. Pashirova, A.B. Mirgorodskaya, O.G. Sinyashin, Self-assembly strategy for the design of soft nanocontainers with controlled properties, Mend. Communication, 26 (6) (2016) 457-468.

[9] L.Ya. Zakharova, A.B Mirgorodskaya, G.A. Gaynanova, R.R. Kashapov, T.N. Pashirova, E.A. Vasilieva, Y.F. Zuev, O.G. Synyashin, Supramolecular strategy of the encapsulation of low molecular weight food ingredients, in: A.M. Grumezescu (Ed.), Encapsulations, Elsevier Inc., Bucharest, 2016, p.p. 295-362.

[10] M.D. Mashkovski, Lekarstvennye sredstva [Medicines], 15th ed., Novaya Volna, Moscow, 2012, 1216 p. (in Russian). 
[11] N. Chadha, O. Silakari, Indoles as therapeutics of interest in medicinal chemistry: Bird's eye view, Eur. J. Med. Chem. 134 (2017) 159-184.

[12] L. Borka, Polymorphism of indomethacin. New modifications, their melting behavior and solubility, Acta Pharm. Suecica 11 (1974) 295-303.

[13] N. Kaneniwa, M. Otsuka, T. Hayashi, Physicochemical characterization of indomethacin polymorphs and the transformation kinetics in ethanol, Chem. Pharm. Bull. 33 (1985) 3447-3455.

[14] M. Otsuka, F.Kato, Y. Matsuda, Y. Ozaki, Comparative determination of polymorphs of indomethacin in powders and tablets by chemometrical near-infrared spectroscopy and X-ray powder diffractometry, AAPS PharmSciTech. 4 (2003) 58-69.

[15] A. Patel, K. Cholkar, V. Agrahari, A. K Mitra, Ocular drug delivery systems: An overview. World J. Pharmacol. 2 (2) (2013) 47-64.

[16] M.A. Ruidiaz, D.R. Delgado, C.P. Mora, A. Yurquina, F. Martínez, Estimation of the indomethacin solubility in ethanol+water mixtures by the extended Hildebrand solubility approach, Rev. Colomb. Cienc. Quím. Farm. 39 (2010) 79-95.

[17] S.P. Balguri, G.R. Adelli, S. Majumdar, Topical ophthalmic lipid nanoparticle formulations (SLN, NLC) of indomethacin for delivery to the posterior segment ocular tissues, Eur. J. Pharm. Biopharm. 109 (2016) 224-235.

[18] A. Froelich, T. Osmałek, A. Snela, P. Kunstman, B. Jadach, M. Olejniczak, G. Roszak, W. Białas. Novel microemulsion-based gels for topical delivery of indomethacin: Formulation, physicochemical properties and in vitro drug release studies, J. Colloid Interface Sci. 507 (2017) 323-336.

[19] S.P. Chaudhari, R.P. Dugar, Application of surfactants in solid dispersion technology for improving solubility of poorly water soluble drugs, J. Drug Delivery Sci. Technol. 41 (2017) $68-77$.

[20] J. Lina, Zh. Pan, L. Song, Y. Zhang, Y. Li, Z. Houa, Ch. Lina, Design and in vitro evaluation of self-assembled indometacin prodrug nanoparticles for sustained/controlled release and reduced normal cell toxicity, Appl. Surf. Sci. 425 (2017) 674-681.

[21] R. I. Moustafine, A.Y. Sitenkov, A.V. Bukhovets, S.F. Nasibullin, B. Appeltans, T.V. Kabanova, V.V. Khutoryanskiy, G. Van den Mooter, Indomethacin-containing interpolyelectrolyte complexes based on Eudragit ${ }^{\circledR}$ E PO/S 100 copolymers as a novel drug delivery system, Int. J. Pharm., 524 (2017) 121-133. 
[22] A.B. Mirgorodskaya, L.Ya Zakharova, E.I. Khairutdinova, S.S. Lukashenko, O.G. Sinyashin, Supramolecular systems based on gemini surfactants for enhancing solubility of spectral probes and drugs in aqueous solution, Colloids Surf., A 510 (2016) 33-42.

[23] E.I. Yackevich, A.B. Mirgorodskaya, L.Ya. Zakharova, O.G. Sinyashin, Solubility and hydrolytic stability of indomethacin in aqueous micellar solutions, Russ. Chem. Bull. 9 (2015) 2232-2237.

[24] E.L. Tan, J.-Ch. Lid, Y.W. Chien, Effect of cationic surfactants on the transdermal permeation of ionized indomethacin, Drug Dev. Ind. Pharm. 19 (1993) 685-699.

[25] J. Shokri, A. Nokhodchi, A. Dashbolaghi, D. Hassan-Zadeh, T. Ghafourian, M.B. Jalali, The effect of surfactants on the skin penetration of diazepam, Int. J. Pharm. 228 (2001) 99-107.

[26] S. Klang, M. Abdulrazik, S. Benita, Influence of emulsion droplet surface charge on indomethacin ocular tissue distribution, Pharm. Dev. Technol. 5 (2000) 521-532.

[27] Ph. Daull, F. Lallemand, J.S. Garrigue, Benefits of cetalkonium chloride cationic oil-inwater nanoemulsions for topical ophthalmic drug delivery, J. Pharm. Pharmacol. 66 (2014) $531-541$.

[28] S. De Koker, L.J. De Cock, P. Rivera-Gil, W.J. Parak, R.A. Velty, Ch. Vervaet, J.P. Remon, J. Grooten, B.G. De Geest, Polymeric multilayer capsules delivering biotherapeutics, Adv. Drug Delivery Rev. 63 (2011) 748-761.

[29] M. Björnmalm, J. Cui, N. Bertleff-Zieschang, D. Song, M. Faria, M.A. Rahim, F. Caruso, Nanoengineering particles through template assembly, Chem. Mater. 29 (2017) 289-306.

[30] M.M. de Villiers, D.P. Otto, S.J. Strydom, Y.M. Lvov, Introduction to nanocoatings produced by layer-by-layer (LbL) self-assembly, Adv. Drug Delivery Rev. 63 (2011) 701-715.

[31] L.Ya. Zakharova, A.R. Ibragimova, E.A. Vasilieva, A.B Mirgorodskaya, E.I. Yackevich, I.R. Nizameev, M.K. Kadirov, Yu.F. Zuev, A.I. Konovalov, Polyelectrolyte capsules with tunable shell behavior fabricated by the simple lbl technique for the control of the release and reactivity of small guests, J. Phys. Chem. 116 (2012) 18865-18872.

[32] E.A. Vasilieva, G.A. Gaynanova, A.B. Mirgorodskaya, A.R. Ibragimova, V.V. Salnikov, I.F. Uchegbu, A.I. Konovalov, Yu.F. Zuev, L.Ya. Zakharova, The polyacrylic acid/modified chitosan capsules with tunable release of small hydrophobic guests, Colloids Surf., A 471 (2015) 93-100.

[33] A.R. Ibragimova, A.B. Mirgorodskaya, E.A. Vasilieva, E.I. Khairutdinova, T.K. Meleshko, I.V. Ivanov, A.V. Yakimansky, L.Y. Zakharova, Polyelectrolyte nanocapsules with controlled 
properties fabricated by layer-by-layer deposition of polyethyleneimine and graft-copolyimide with polymethacrylic acid side chains, Colloids Surf., A 526 (2017) 20-28.

[34] G.B. Sukhorukov, A.L. Rogach, M. Garstka, S. Springer, W.J. Parak, A. Munoz-Javier, O. Kreft, A.G. Skirtach, A.S. Susha, Y. Ramaye, R. Palankar, M. Winterhalter, Multifunctionalized polymer microcapsules: novel tools for biological and pharmacological applications, Small 3 (2007) 944-955.

[35] M.M. de Villiers, D.P. Otto, S.J. Strydom, Y.M. Lvov, Introduction to nanocoatings produced by layer-by-layer (LbL) self-assembly, Adv. Drug Delivery Rev. 63 (2011) 701-715.

[36] J.J. Richardson, J. Cui, M. Björnmalm, Ju.A. Braunger, H. Ejima, F. Caruso, Innovation in layer-by-layer assembly, Chem. Rev. 116(23) (2016) 14828-14867.

[37] R. Luo, S.S. Venkatraman, B. Neu, Layer-by-layer polyelectrolyte-polyester hybrid microcapsules for encapsulation and delivery of hydrophobic drugs, Biomacromolecules 14 (7) (2013) 2262-2271.

[38] S. Aziz, J. Gill, P. Dutilleul, R. Neufeld, S. Kermasha, Microencapsulation of krill oil using complex coacervation, J. Microencapsul. 31 (2014) 774-784.

[39] J. Cui, M.P. van Koeverden, M. Müllner, K. Kempe, F. Caruso, Emerging methods for the fabrication of polymer capsules, Adv. Colloid Interface Sci. 207 (2014) 14-31.

[40] M. Kukut, O. Karal-Yilmaz, Yu. Yagci, Synthesis, characterisation and drug release properties of microspheres of polystyrene with aliphatic polyester side-chain, J. Microencapsul. 31(3) (2014) 254-261.

[41] O. Shimoni, Ya. Yan, Ya. Wang, F. Caruso, Shape-dependent cellular processing of polyelectrolyte capsules, ACS Nano 7 (2013) 522-530.

[42] M.N. Antipina, G.B. Sukhorukov, Remote control over guidance and release properties of composite polyelectrolyte based capsules, Adv. Drug Delivery Rev. 63 (2011) 716-729.

[43] A.N. Kuskov, P.P. Kulikov, A.V. Goryachaya, M.N. Tzatzarakis, A.O. Docea, K.Velonia, M.I. Shtilman, A.M. Tsatsakis, Porous calcium carbonate microparticles as templates for encapsulation of bioactive compounds, J. Mater. Chem. 14 (2004) 2073-2081.

[44] A. Sundaramurthy, A.K. Sundramoorthy, Polyelectrolyte capsules preloaded with interconnected alginate matrix: An effective capsule system for encapsulation and release of macromolecules. Int. J. Biol. Macromol., 107 (2018) 2251-2261. 
[45] D. Zhou, H. Xiao, F. Meng, Sh. Zhou, J. Guo, X. Li, X. Jing, Yu. Huang, Layer-by-layer assembled polypeptide capsules for platinum-based pro-drug delivery, Bioconjugate Chem. 23 (2012) 2335-2343.

[46] H. Ai, Layer-by-layer capsules for magnetic resonance imaging and drug delivery, Adv. Drug Delivery Rev. 63 (2011) 772-788.

[47] V. Vergaro, F. Scarlino, C. Bellomo, R. Rinaldi, D. Vergara, M. Maffia, F. Baldassarre, G. Giannelli, X. Zhang, Yu. M. Lvov, S. Leporatti, Drug-loaded polyelectrolyte microcapsules for sustained targeting of cancer cells, Adv. Drug Delivery Rev. 63 (2011) 847-864.

[48] E.A. Vasilieva, A.R. Ibragimova, A.B. Mirgorodskaya, E.I. Yackevich, A.B. Dobrynin, I.R. Nizameev, M.K. Kadirov, L.Ya. Zakharova, Yu.F. Zuev, A.I. Konovalov, Polyelectrolyte microand nanocapsules with varied shell permeability controlling the rate of esters hydrolysis, Russ. Chem. Bull. 63 (2014) 232-238.

[49] U. Manna, S. Patil, Encapsulation of uncharged water-insoluble organic substance in polymeric membrane capsules via layer-by-layer approach, J. Phys. Chem. B 112 (2008) 1325813262.

[50] A.B. Mirgorodskaya, L.A. Kudryavtseva, V.A. Pankratov, S.S. Lukashenko, L.Z. Rizvanova, A.I. Konovalov, Geminal alkylammonium surfactants: Aggregation properties and catalytic activity Russ. J.Gen. Chem. 76 (2006) 1625-131.

[51] Rukovodstvo po provedeniju doklinicheskih issledovaniy lekarstvennuh sredstv, Chast' 1. Pod redaktziey A.N. Mironova, GrifiK, M., 2012, 944.

[52] I.V. Berezovskaya, Classification of substances with respect to acute toxicity for parenteral administration, Pharm. Chem. J. 37 (2003) 139-142.

[53] P.L. Carpenter. In: Immunology and Serology, 3rd ed. W.B. Sounders Company, Philadelphia, London, Toronto. 1975, 254.

[54] A. Nokhodchi, Y. Javadzadeh, M. R. Siahi-Shadbad, M. Barzegar-Jalali, The effect of type and concentration of vehicles on the dissolution rate of a poorly soluble drug (indomethacin) from liquisolid compacts, J. Pharm. Pharm. Sci. 8 (2005) 18-25.

[55] V.V. Khutoryanskiy, Advances in mucoadhesion and mucoadhesive polymers, Macromol. Biosci., 11 (2011) 748-764.

[56] J. Siepmann, N.A. Peppas, Modeling of drug release from delivery systems based on hydroxypropyl methylcellulose (HPMC). Adv. Drug Delivery Rev., 48 (2001) 139-57.

[57] M.L. Bruschi, Strategies to modify the drug release from pharmaceutical systems, Woodhead Publishing, 2015, 208. 
[58] D.Y. Arifin, L.Y. Lee, C.H. Wang, Mathematical modeling and simulation of drug release from microspheres: Implications to drug delivery systems, Adv. Drug Delivery Rev., 58 (2006) $1274-1325$.

[59] J.M. Unagolla, A.C. Jayasuriya, Drug transport mechanisms and in vitro release kinetics of vancomycin encapsulated chitosan-alginate polyelectrolyte microparticles as a controlled drug delivery system, Eur. J. Pharm Sci., 114 (2018) 199-209.

[60] A.N. Kuskov, P.P. Kulikov, A.V. Goryachaya, M.N. Tzatzarakis, A.O. Docea, K.Velonia, M.I. Shtilman, A.M. Tsatsakis, Polymeric nanoparticles were prepared from self-assembled amphiphilic $\mathrm{N}$-vinylpyrrolidone polymers in aqueous media and evaluated as novel carriers of indomethacin, Nanomedicine: Nanotechnology, Biology and Medicine, 13 (2017) 1021-1030.

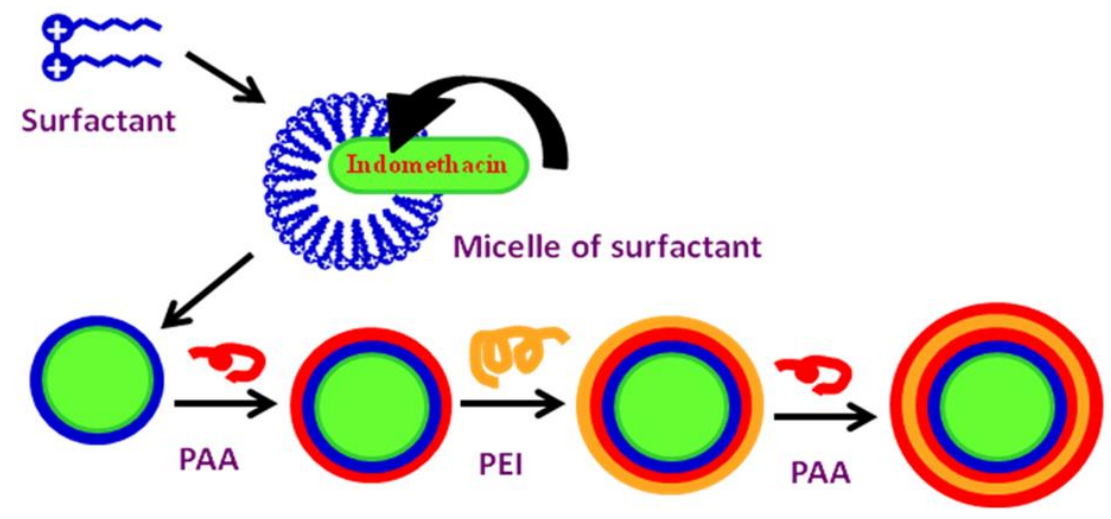

Fig.1. Scheme of formation of polyelectrolyte capsules.

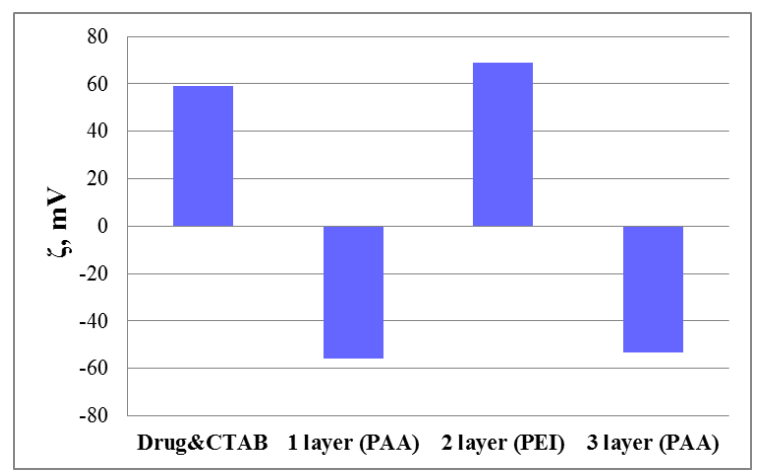

Fig.2. Change of zeta-potential of particles during capsule formation. 


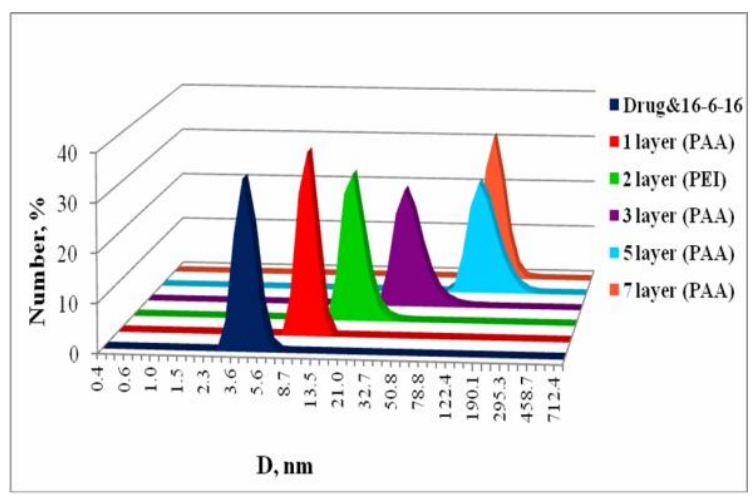

Fig.3. Change of hydrodynamic diameter of 16-6-16/PAA/PEI capsules loaded with indomethacin after each deposited layer of polyelectrolytes.

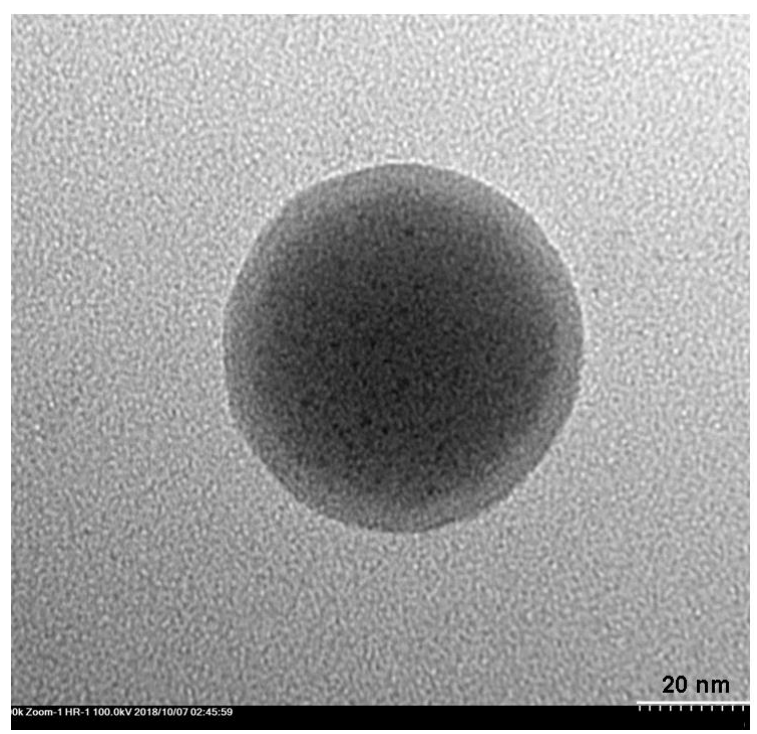

Fig.4. TEM images of 3-layered capsules 16-6-16/PAA/PEI loaded with indomethacin.

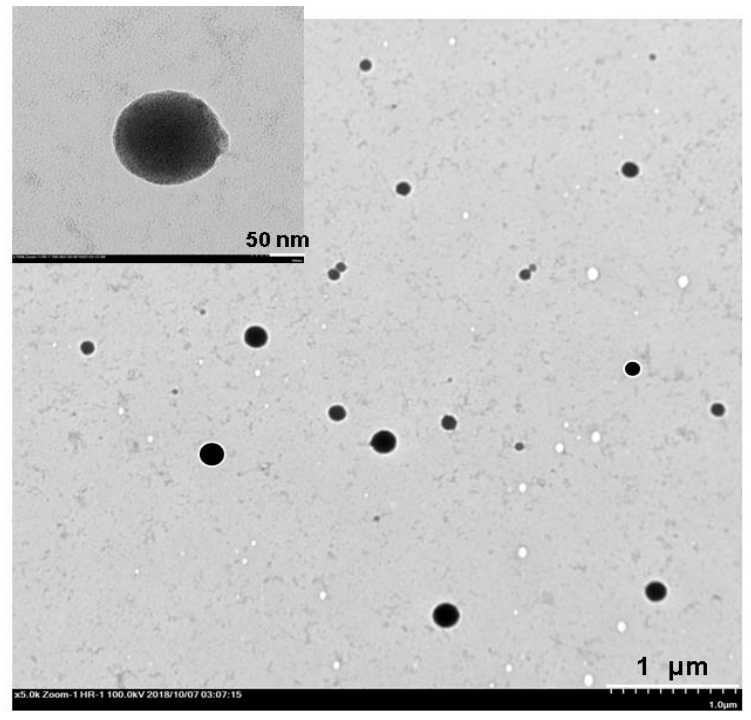

Fig.5. TEM images of 5-layered capsules 16-6-16/PAA/PEI loaded with indomethacin. 


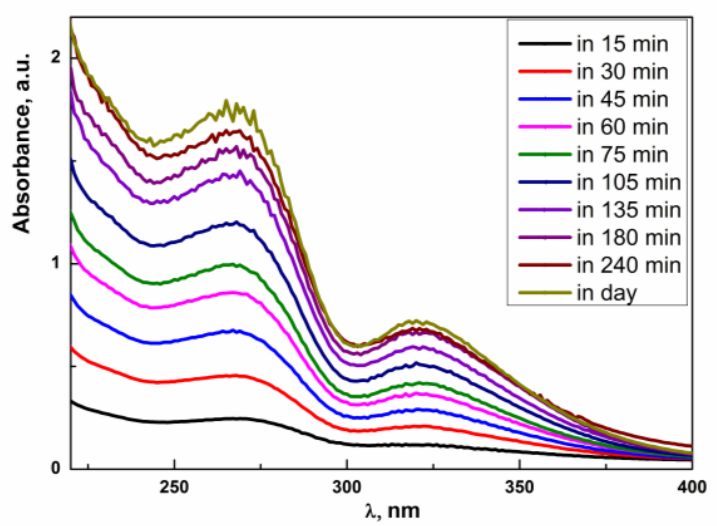

Fig.6. Change in the absorbance of dialysate solutions (indomethacin) with time (three-layered capsules based on $\mathrm{CTAB} / \mathrm{PAA} / \mathrm{PEI}, 37^{\circ} \mathrm{C}, \mathrm{pH}$ 7).

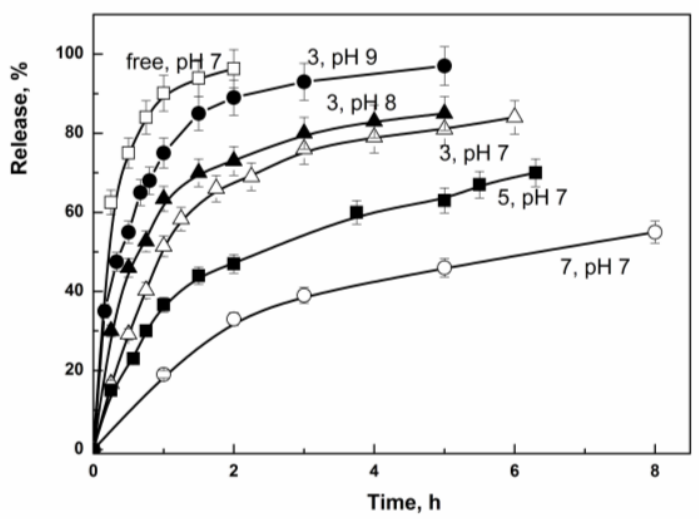

Fig.7. Release of free and encapsulated indomethacin from dialysis bag (three-, five-, and sevenlayered capsules 16-6-16/PAA/PEI, $37^{\circ} \mathrm{C}$, pH 7-9).

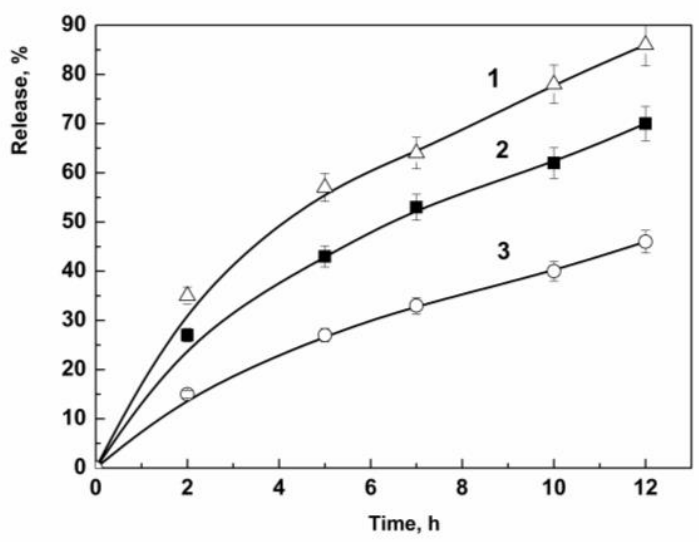

Fig.8. Release of indomethacin from three-layered capsules 16-6-16/PAA/chitosan at pH 8 (1), $\mathrm{pH} 7$ (2), as well as from the five-layered capsules at $\mathrm{pH} 7(3)\left(37^{\circ} \mathrm{C}\right)$. 

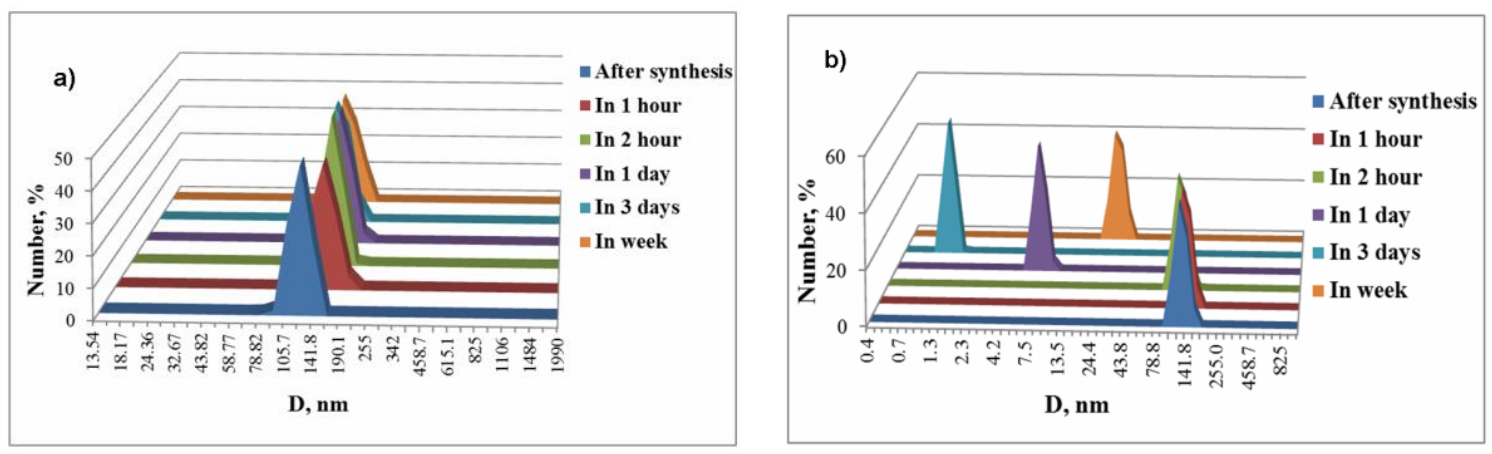

Fig.9. Changes in particle size distributions of three-layered capsules with time at $\mathrm{pH} 7$ (a), $\mathrm{pH}$ 9.2 (b). 


\title{
Supplementary material
}

\section{Polyelectrolyte nanocontainers: controlled binding and release of indomethacin.}

\begin{abstract}
Alla B. Mirgorodskaya ${ }^{a, b}$, Rushana A. Kushnazarova ${ }^{a}$, Anastasiya V. Nikitina ${ }^{c}$, Irina I. Semina ${ }^{c}$, Irek R. Nizameev ${ }^{a}$, Marsil K. Kadirova, Vitaliy V. Khutoryanskiy ${ }^{\text {, }}$ Lucia Ya. Zakharova ${ }^{\text {a,b }}$, Oleg G.Sinyashin ${ }^{\text {a,b }}$
\end{abstract}

${ }^{a}$ Arbuzov Institute of Organic and Physical Chemistry of FRC Kazan Scientific Center of RAS, 8 Arbuzov street, Kazan, 420088, Russian Federation

${ }^{\mathrm{b}}$ Kazan National Research Technological University, 68 K. Marx street, Kazan, 420015, Russian Federation

${ }^{c}$ Kazan State Medical University, 49, Butlerov street Kazan, 420012, Russian Federation

${ }^{\mathrm{d}}$ School of Pharmacy, University of Reading, Whiteknights, PO Box 224, Reading, RG6 6AD, United Kingdom

Corresponding author: Alla Mirgorodskaya; Telephone: +7(843) 27322 93;

Fax: +7(843) 27322 53; 8, ul.Akad. Arbuzov, Kazan, 420088, Russia;

e-mail:mirgoralla@mail.ru, mirgorod@iopc.ru

\section{The synthesis of hexamethylene-1,6-bis(dimethylhexadecylammonium dibromide (16-6-16)}

16-6-16 was synthesized by the reaction of $\mathrm{N}, \mathrm{N}, \mathrm{N}^{\prime}, \mathrm{N}^{\prime}$-tetramethyl-1,6hexamethylenediamine $(0.01 \mathrm{~mol})$ with excess $n$-hexadecyl bromide $(0.022 \mathrm{~mol})$ in acetone. The mixture was stirred in the flask equipped with a reflux condenser for $8 \mathrm{~h}$ at $56{ }^{\circ} \mathrm{C}$, then the precipitate formed was recrystallized twice from ethyl alcohol. Yield $85 \%$.

The synthesized compound was characterized by the following data: elemental analysis: for $\mathrm{C}_{42} \mathrm{H}_{90} \mathrm{~N}_{2} \mathrm{Br}_{2}$ calculated (\%): C 64.42, H 11.58, N 3.57, Br 20.41; found (\%): C 64.30,H 12.13, N 3.56, $\mathrm{Br} 20.90$; melting temperature of $203-204^{\circ} \mathrm{C}$. IR spectrum $(\mathrm{KBr}), \mathrm{v} / \mathrm{cm}^{-1}: 3432,3006$, 2920, 2852, 1495, 1471, 1396, 985, 946, 925, 785, 724. 1H NMR spectra were recorded by using Bruker AVANCE 600 and Bruker AVANCE II 400 instruments. 1H NMR $\left(\mathrm{CDCl}_{3}, \delta\right.$, ppm; J, $\mathrm{Hz}) \quad 0.87\left[\mathrm{t}, \quad 6 \mathrm{H}, \quad 2 \mathrm{xN}^{+} \mathrm{CH}_{2}\left(\mathrm{CH}_{2}\right)_{13} \mathrm{CH}_{2} \underline{\mathrm{CH}}_{3}, J=6.90\right] ; 1.24-1.33 \quad[$ br $\mathrm{m}, \quad 52 \mathrm{H}$, $\left.2 \mathrm{xN}^{+} \mathrm{CH}_{2}\left(\underline{\mathrm{CH}}_{2}\right)_{13} \mathrm{CH}_{2} \mathrm{CH}_{3}\right)$ ]; 1.56 [br s, $\left.4 \mathrm{H}, 2 \mathrm{xN}^{+} \mathrm{CH}_{2}\left(\mathrm{CH}_{2}\right)_{13} \underline{\mathrm{CH}_{2}} \mathrm{CH}_{3}\right)$ ]; 1.69 [br m, 4H, $\left.\mathrm{N}^{+} \mathrm{CH}_{2} \underline{\mathrm{CH}}_{2}\left(\mathrm{CH}_{2}\right)_{2} \underline{\mathrm{CH}}_{2} \mathrm{CH}_{2} \mathrm{~N}^{+}\right] ; 1.96$ [br m, 4H, N $\mathrm{CH}_{2} \mathrm{CH}_{2}\left(\underline{\mathrm{CH}_{2}}\right)_{2} \mathrm{CH}_{2} \mathrm{CH}_{2} \mathrm{~N}^{+}$]; 3.36 [s, 12H, $\left.2 \mathrm{xN}^{+}\left(\underline{\mathrm{CH}_{3}}\right)_{2}\right] ; \quad 3.46 \quad\left[\mathrm{~m}, \quad 4 \mathrm{H}, \quad 2 \mathrm{xN}^{+} \underline{\mathrm{CH}_{2}}\left(\mathrm{CH}_{2}\right)_{13} \mathrm{CH}_{2} \mathrm{CH}_{3}\right] ; \quad 3.67 \quad[\mathrm{~m}, \quad 4 \mathrm{H}$, $\left.\mathrm{N}^{+} \underline{\mathrm{CH}}_{2} \mathrm{CH}_{2}\left(\mathrm{CH}_{2}\right)_{2} \mathrm{CH}_{2} \underline{\mathrm{CH}}_{2} \mathrm{~N}^{+}\right]$ 


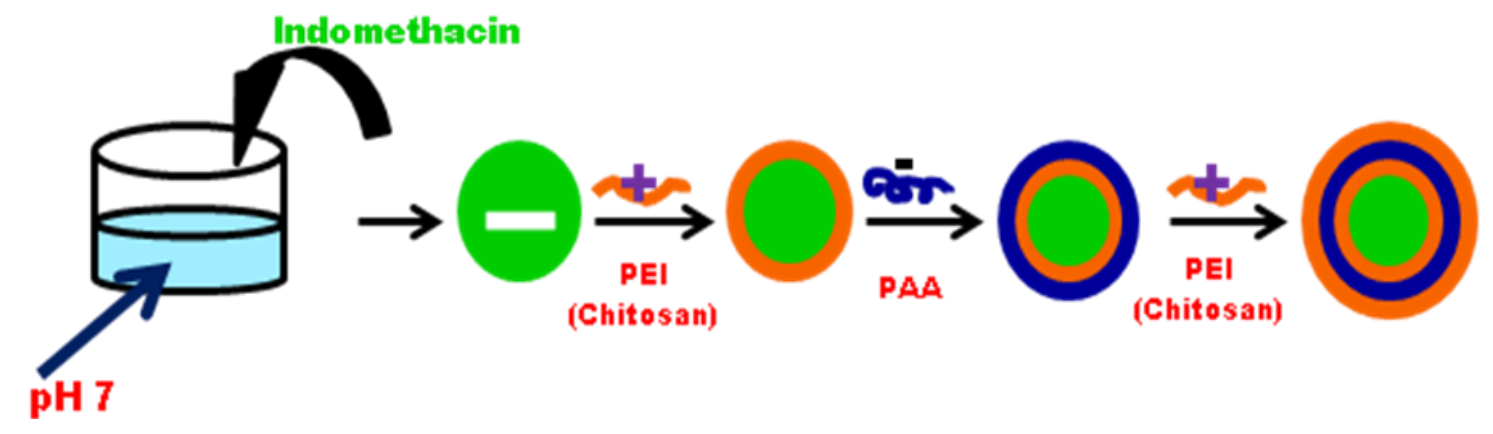

Fig.S1. Scheme of formation of polyelectrolyte capsules by direct deposition of polyelectrolytes onto indomethacin dispersed in water

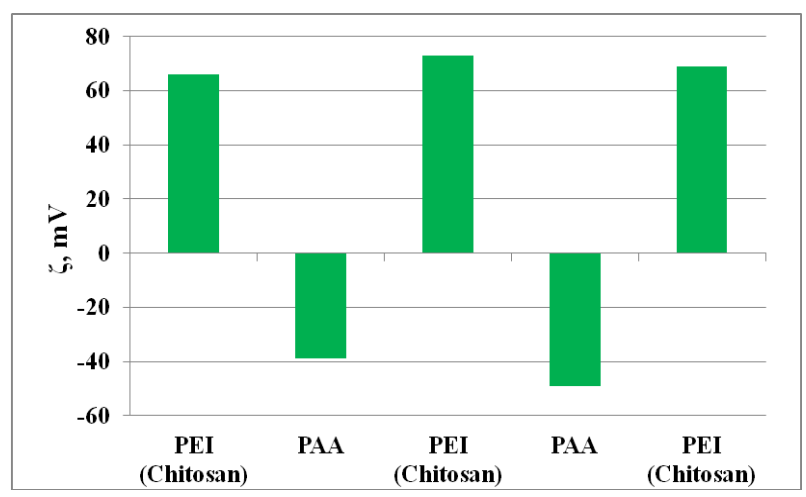

Fig.S2. Change of zeta-potential of particles during capsule formation by direct deposition of polyelectrolytes onto indomethacin dispersed in water 


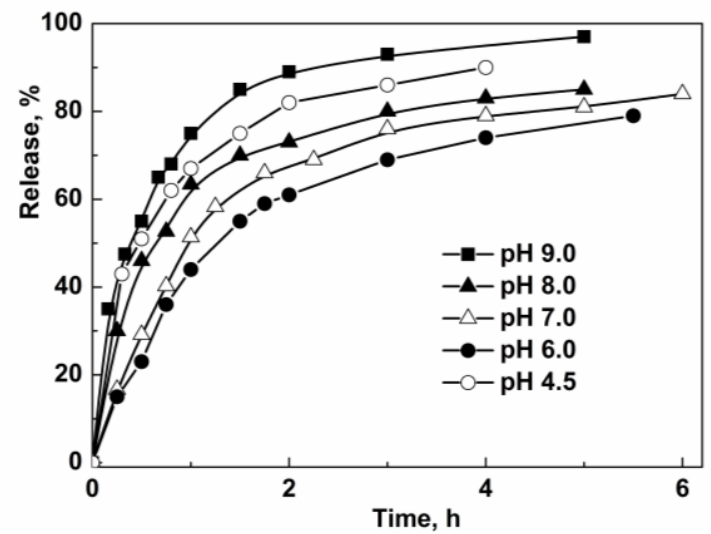

Fig. S3. Release encapsulated indomethacin from dialysis bag at different $\mathrm{pH}$ (three-layered capsules 16-6-16/PAA/PEI, $37^{\circ} \mathrm{C}$ )

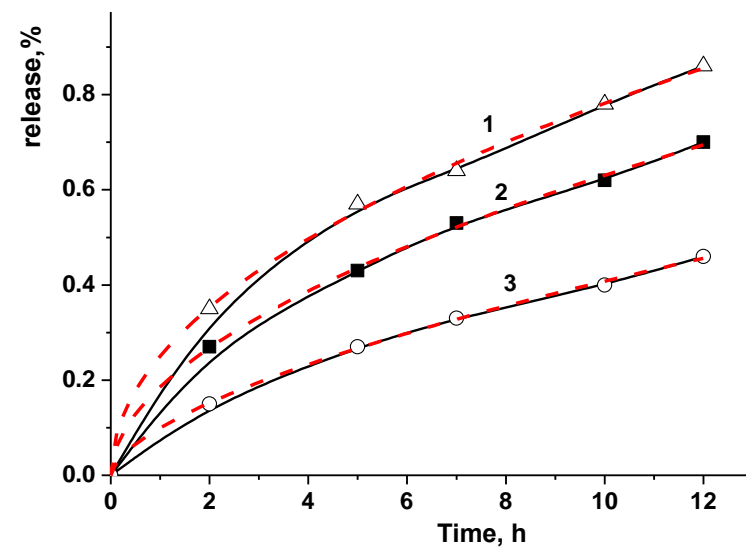

Fig.S3. Release of indomethacin from three-layered capsules PAA/chitosan at $\mathrm{pH} 8$ (1), $\mathrm{pH} 7$ (2), as well as from the five-layered capsules at $\mathrm{pH} 7(3)\left(37^{\circ} \mathrm{C}\right)$. Predicted data from equation Ritger-Peppas are given by dashed lines. 